\title{
An Interdisciplinary Practical for Multimedia Engineering Students
}

\author{
Diego Marcos-Jorquera, María Luisa Pertegal-Felices, Antonio Jimeno-Morenilla, Member, IEEE, and \\ Raquel Gilar-Corbí
}

\begin{abstract}
Interdisciplinary projects in the industry typically require collaboration between professionals from various fields. However, this relationship is not generally addressed in the training offered by university programs, which often ignore this interdisciplinary approach. This paper offers an example of interdisciplinary interaction through joint laboratory activities in the curricula of two very different degree programs, i.e., Multimedia Engineering and Teacher Training in Primary Education. The programs' students formed an interdisciplinary team of multimedia engineers and trainee teachers to develop a Web product for children's cognitive development. The complexity of the task required students to engage in close and strong interdisciplinary cooperation and communication; in turn, they benefited from the synergy offered by collaborative work. The results of this paper, presented from the perspective of the multimedia engineering students, demonstrate a significant increase in their academic performance compared to the control group. This paper shows that university studies can incorporate an interdisciplinary perspective to engineering education without the need to introduce a specific course on the topic, thus avoiding further demands on the curriculum schedule.
\end{abstract}

Index Terms-Design of activities, interdisciplinary practices, multimedia, teaching methodology.

\section{INTRODUCTION}

\section{A. Skills and Professional Success}

$\mathbf{V}$ ARIOUS studies have pointed to the emergence of a new professional profile in organizations [1]-[4]. Essentially, an individual with this profile has various types of knowledge, e.g., operational; technological, particularly in computing; management and administration; social; and, finally, emotional. The emergence of this new type of professional is not coincidental: It is an inevitable outcome of the shift to a "knowledge society." The application of various kinds of knowledge to solve a range of problems has always played a central role in economic development and social welfare. The relatively modern concept of the knowledge society, however, refers to a society in which knowledge, rather than manual work, raw materials, and capital, is the most important source of economic and social

Manuscript received May 5, 2015; revised September 25, 2015, December 2, 2015, and March 22, 2016; accepted April 30, 2016. This work was supported in part by the University of Alicante under Grant GRE14-16.

D. Marcos-Jorquera and A. Jimeno-Morenilla are with the Department of Computer Technology, University of Alicante, 03690 Alicante, Spain.

M. L. Pertegal-Felices and R. Gilar-Corbí are with the Department of Development Psychology and Teaching, University of Alicante, 03690 Alicante, Spain (e-mail: ml.pertegal@ua.es).

Color versions of one or more of the figures in this paper are available online at http://ieeexplore.ieee.org.

Digital Object Identifier 10.1109/TE.2016.2566606 development [5]. The knowledge society demands certain skills from its citizens so that they can function in the complex web of knowledge, technology, communication, and cooperation that has replaced the traditional monodisciplinary professions. The business world's awareness of this, as well as their quest for maximum worker performance, has fostered research on the skills characteristic of the most successful employees.

Analyzing these capabilities, various authors [6]-[8] have concluded that social and emotional intelligence are part of the complex web of skills required to perform successfully in professional fields [9], [10]. Emotional intelligence (EI) has been conceptualized under two main models. First, ability models [11] define EI as a type of social intelligence that allows an individual to be aware of their own feelings and emotions and those of others, of discriminating between them, and of using this information to guide thinking and actions. Second, mixed models combine cognitive competencies with interpersonal competencies, social skills, and other dispositional factors (such as optimism or motivation) and define EI as a set of competencies that enables individuals to be more effective in responding to job requirements [9], [12], [13]. The relationship between interpersonal skills and performance has been shown by numerous investigations, among which the study by Koman and Wolff [14] stands out.

Some studies underline that an individual's ability to adapt to his or her surroundings could be determined by their mastery of interpersonal skills and the ability to work with professionals from other fields [8], [14], [15]. Effective adaptation can enable professional success, but poor adaptation can have negative professional consequences such as burnout. Good management of stress or other emotional variables avoids or reduces stress or depression in the workplace [16].

These skills not only influence professional performance but also have an impact on successful searches for employment [17]. Burns et al. [18], after analyzing the relationship between employability and professionalism, conclude that the specific knowledge acquired while pursuing a university degree is often insufficient to guarantee employment. Some competences have been identified as predictors of a successful pursuit of employment [19].

\section{B. Generic Skills and the University}

A generic skill, synonymous with "transferrable skill," is applicable across a variety of subject domains and can be identified in various degree programs at any given level [20]. In industry, companies offer training in these skills partly because 
the traditional schemes of higher education ignore competences that are not degree-specific [21], [22]. It is important to remember that universities, as educational and training institutions, play a key role in ensuring that citizens acquire the key competences necessary to adapt well to a changing professional reality.

The Bologna Declaration emphasizes the importance of education (particularly in students' acquisition of skills, abilities, competences, and values) by adopting a new methodology oriented toward the learning of competences, particularly interpersonal competences. The Tuning Educational Structures in Europe Project [20], [23] develops professional profiles, learning outcomes, and desirable competences in terms of generic competences and those relating to each area of study. It defined 30 generic competences grouped into three blocks. First, instrumental competences comprise cognitive capacities (analyzing, understanding, and handling ideas), methodological capacities (ability to organize one's own learning process and make decisions), technological skills, (ability to use technological services), and linguistic services. Second, interpersonal competences include individual capacities (expressing emotions and self-criticism) and social skills (interpersonal skills, teamwork, and social responsibility or ethical commitment). Third, systemic competences describe the integration of the above competences, such as management skills or creativity. Some of these competences relate social skills and interpersonal skills such as the ability to work in teams.

In the professional field of engineering, the Career Space Project [24] was developed with the support of the European Commission, by the Career Space consortium. This consisted of 11 large information and communication technology (ICT) companies and the European Information and Communications Technology Industry Association (EICTA). The Career Space Project provides a series of guidelines and recommendations for the development of curricular programs, analyzing 100 ICT programs of study in nine European countries. This project states that "(ICT graduates) need training in team working, with real experience of team projects where several activities are undertaken in parallel ... In addition, ICT graduates need to have good personal skills such as problem-solving abilities, awareness of the need for lifelong learning, readiness to understand fully the needs of the customer and their project colleagues, and awareness of cultural differences when acting in a global environment." Applying this conclusion to the varied work environments of both multimedia engineers and teachers, it becomes clear that teamwork competences ensure better integration of the individual into the workplace, enabling higher job performance [25]. Individuals in the computing field have been shown to perform below the desirable level in bringing interpersonal skills such as teamwork to performing professional tasks [3].

Finally, successful implementation of training in generic skills depends on the involvement and collaboration of the entire educational community [26], [27]. Schools where training in social and emotional competences is most developed have faced many obstacles [28]. When these are taught in specific courses [29], for instance, "EI" courses, this reduces the time available for other courses, thus potentially reducing student academic performance in those areas [30].

\section{Interdisciplinary Versus Multidisciplinary Teams}

Recently, diversity in teams of engineering students has been shown to exert a positive influence on teamwork, in comparison to monodisciplinary teams [25]. For ICT engineers, developing teamwork and team communication skills in interdisciplinary teams is especially necessary since the field, to a large extent, demands professionals who are able to create "products" for clients in any field and/or area.

At times, it can be difficult to distinguish between interdisciplinary and multidisciplinary terms. In the field of engineering, Lattuca and Knight [31] noted serious disparities of criteria between both teachers and students. Here, the definition by Klein and Newell is applied, in which interdisciplinary is " $a$ process of answering a question, solving a problem, or addressing a topic that is too broad or complex to be dealt with adequately by a single discipline or profession... and [that] draws upon disciplinary perspectives and integrates their insights through construction of a more comprehensive perspective" [32, pp. 393-394]. Therefore, whereas the multidisciplinary approach refers to simple serialization of tasks of various disciplines, the interdisciplinary approach implies synthesis or integration of various elements of knowledge of different disciplines within a cohesive whole [31].

Generic skills are strongly related to interdisciplinary teams. Dirsch-Weigand et al. [33] showed how students who worked in interdisciplinary teams gained generic skills. They learned about the methodology of their own field and the profiles of other disciplines, and they developed their responsibility, communication, and teamwork skills.

Richter and Paretti [34] identified barriers to be faced within interdisciplinary teams, saying these could be overcome if faculty adopts meaningful learning outcomes associated with interdisciplinary collaboration and incorporates small exercises and technological tools to address those outcomes.

\section{Project-Based Learning}

Learning is an activity that takes place in a sociocultural context. Therefore, as Vosniadov et al. [35] state, when learning is placed in real-world contexts, the results of that learning are better retained and facilitate transference. Since learning is considered a social issue, schools and colleges should encourage students to work with others and learn from them. This can be done by encouraging students to take part in projects, resolve complex problems, design and perform experiments, think about ideas, listen to the ideas of others, and take control of their learning.

Project-based learning (PBL) is an overall approach to the design of learning environments. Students engage in solving real meaningful problems that are important to them and that are similar to the problems that they will face in their future working environment. Interdisciplinary PBL has a flexible curriculum so that teachers can meet their curriculum mandates while leading students in their own explorations. The students' needs are met by being empowered with the responsibility for their own learning. The process of planning and implementing PBL can be a radical departure from traditional practice for 
teachers and students and may elicit negative responses. Most of these are related to time constraints and planning or to changes in routine, such as the elimination of textbooks or classical classrooms [36].

In PBL, the professional and practical orientation of instruction (PPOI) is a broad concept that includes the professional orientation of the university curriculum, specifically aimed at the development of professional features in each class [37]. A study on a sample of unemployed graduates looking for their first job [38] tested the relationship between PPOI and the intensity of the job search, which is a key factor for finding jobs that match the recent graduates' degrees [39].

\section{E. Designing an Interdisciplinary Team Experience}

Goldman and Petrosino [40] present four principles for the creation of learning environments in interdisciplinary content domains.

1) Instruction is organized around significant learning and appropriate aims. When learning takes place in significant contexts and with appropriate aims, knowledge is more likely to be represented consistently.

2) Instruction should provide a scaffolding to improve significant learning. The instructional goal is to help students to develop strategies that replace the educational support structure, think for themselves, and generalize their own knowledge.

3) Instruction should supply opportunities for feedback, revision, and reflection.

4) Instruction should promote cooperation, sharing of expertise, and open discussion in the community of learners.

In the work reported here, the interdisciplinary team environment was created according to De Corte's recommended learning principles [41], i.e., first, systematic instruction and orientation, and second, learning environments that encourage and support the acquisition of constructive and accumulative goal-oriented processes, through discovery learning and personal exploration. Learning environments should also improve students' self-regulation in their learning processes. To ensure that students increasingly become the agents of their own learning, learning environments were placed in real contexts that were meaningful for them, and this offered plenty of resources and learning material, as well as opportunities for collaboration. Instructional support was adapted to pay attention to students' self-regulation and take into account their individual differences in cognitive aptitudes and in affective and motivational features. The recommendations of Oakley et al. [42] were also adopted, creating guidelines for team functioning, outlining different team roles and the responsibilities of each role, defining work procedures, creating a problem-solving system, and creating a system for assessing progress toward effective team functioning.

The goal of the study reported here was to promote the development of generic competences involved with working in interdisciplinary teams in educational projects. Interdisciplinary activities were proposed and implemented in a Usability and Accessibility (UA) course offered in the Multimedia En- gineering degree program and in a Developmental Psychology (DP) course in the Primary Education Teacher degree program, both at the University of Alicante, Alicante, Spain.

This paper is structured as follows. First, the academic context and the courses in which this teaching experience took place are presented. Then, the design methodology and the detailed assessment process for multimedia students are described. Finally, the results and main findings are presented.

\section{Methodology}

The main goal of the interdisciplinary proposal is to create Web-based multimedia activities that stimulate cognitive skills in primary school children (from 6 to 12 years of age). This paper focuses on the multimedia students of the UA course. For evaluation purposes, these students were divided into two groups, i.e., an experimental group of multimedia students who created the products by collaborating with teaching students in interdisciplinary teams and a control group of multimedia students who created the same products, in monodisciplinary teams, with no contact to students from other degree programs. The learning goals, materials, and assessments were the same for both groups. The UA course is offered each year in several sections on different schedules.

The experimental group for the interdisciplinary experiment was selected from a course section whose schedule coincided with a section of the DP teacher training course, i.e., where the students from both courses were available on the same day and at the same time. The UA section had 47 students enrolled. These were randomly divided to form the experimental and control groups of 23 and 24 students, respectively. These groups then further divided into two- or three-student teams. Three or four DP students were then added to each team in the experimental group to create six-person interdisciplinary teams.

The Web-based activities were classified and documented on the basis of school year and aptitude developed. Specifically, each team had to design and develop eight activities, two from each course level, namely, infant, first, second, and third years. The requirements of each of the activities were determined by the children's course level and were designed to improve their cognitive development. On completion, each activity had to report performance information and the time taken to complete the task to assist professionals in assessing the child's progress.

The experimental group's interdisciplinary teams of teaching and multimedia students were intended to have similar characteristics to those of interdisciplinary teams found in actual working environments. In the teams, the UA multimedia studies students act as technological developers of the educational tool and the DP teacher training students act as designers and supervisors. To ensure effective collaboration between the teaching and multimedia students, faculty incorporated small exercises to overcome any barriers. Both the control and experimental groups carried out the same work, but for the control group, the multimedia teacher designed and specified the educational tools to the same criteria and requirements as in the experimental group.

Subsequently, the main features of this educational intervention are given in detail. 


\section{A. Multimedia Engineering Context}

The Multimedia Engineering degree program merges traditional engineering and computer engineering. Its general objective is to train professionals in the ICT sector capable of directing new multimedia projects in both the leisure and digital entertainment spheres and managing content for dissemination in information networks.

The UA course is a required first-semester course in the first year of the University of Alicante's Multimedia Engineering degree program that has been taught since the 2010-2011 academic year. The course's main objective is to provide students with the necessary concepts and tools to design and develop multimedia products with usability features that make using and learning these projects easier and accessibility features that allow users to access them whatever their status, ability, or situation.

The UA students' task in this work focused on the multimedia aspects of creating the application interface, particularly stressing the activity's ease of use and learning (usability) and ensuring access to end-users (accessibility). During product development, it was emphasized that the product users would be children between 6 and 12 years of age, a fact that would notably affect the type of interface used.

The Appendix presents the degree-specific skills that this project attempts to develop (see Table VII), the course goals corresponding to the practical work carried out in this study (see Table VIII), and the learning results in this course (see Table IX).

\section{B. Joint Planning}

One of the most important aspects while implementing the interdisciplinary sessions was to plan the session calendars of both courses to allow for four joint practical sessions. The UA course had 15 sessions in the semester, and the DP course had 14 sessions. The joint practical sessions were held in weeks 7, 9,11 , and 15 of the 15-week semester. In addition, each team, whether interdisciplinary or monodisciplinary, was permitted to organize as many working meetings as necessary to complete the project. Table I gives the schedule for the interdisciplinary sessions.

During their first six sessions of the semester, the UA students developed a Web-based product of low complexity, unrelated to the product to be developed in the joint sessions. This initial development activity gives students the basic skills necessary to successfully cope with the development of the Web-based activity to be developed in weeks $7-15$ of the semester.

\section{Coordination Mechanisms}

To ensure smooth development of the laboratory activities and adherence to the planned schedule, mechanisms were put in place for coordination between team members, i.e., both intrateam (students belonging to the same course) and interteam (students of both courses). Within each team (in both experimental and control groups), one student was given the
TABLE I

SCHEDULE FOR JOINT INTERDISCIPLINARY COURSE SESSIONS

\begin{tabular}{|c|c|c|c|}
\hline WEEK & Product & UA Sessions & DP Sessions \\
\hline 1 & \multirow{6}{*}{ 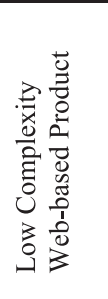 } & $\begin{array}{l}\text { Sessions 1-5: Development } \\
\text { of low-complexity web }\end{array}$ & \multirow{5}{*}{$1^{\text {st }}$ Session } \\
\hline 2 & & & \\
\hline 3 & & & \\
\hline 4 & & & \\
\hline 5 & & & \\
\hline 6 & & $\begin{array}{l}6^{\text {th }} \text { Session: Submission of } \\
\text { first web product }\end{array}$ & \\
\hline 7 & & $7^{\text {th }}$ Session: taking & $6^{\text {th }}$ Session: \\
\hline 8 & 矛 & application requirements & application request \\
\hline 9 & 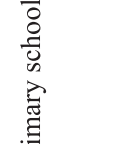 & $\begin{array}{l}9^{\text {th }} \text { Session: Submission of } \\
\text { application specification }\end{array}$ & $\begin{array}{l}8^{\text {th }} \text { Session: } \\
\text { submission of } \\
\text { materials and } \\
\text { specifications }\end{array}$ \\
\hline 10 & ㄹ. & & \\
\hline 11 & 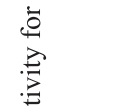 & $\begin{array}{l}11^{\text {th }} \text { Session: design } \\
\text { submission (sketch) }\end{array}$ & $\begin{array}{l}10^{\text {th }} \text { Session: content } \\
\text { review and } \\
\text { modifications. }\end{array}$ \\
\hline $12-14$ & 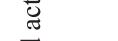 & & \\
\hline 15 & $\begin{array}{l}\overrightarrow{0} \\
0 \\
0 \\
0 \\
0 \\
1 \\
0 \\
0 \\
3\end{array}$ & $\begin{array}{l}15^{\text {th }} \text { Session: Submission of } \\
\text { the final product, } \\
\text { presentation, and assessment }\end{array}$ & $\begin{array}{l}14^{\text {th }} \text { Session: } \\
\text { Submission and } \\
\text { assessment of the } \\
\text { website. }\end{array}$ \\
\hline 16 & & & $15^{\text {th }}$ Session \\
\hline
\end{tabular}

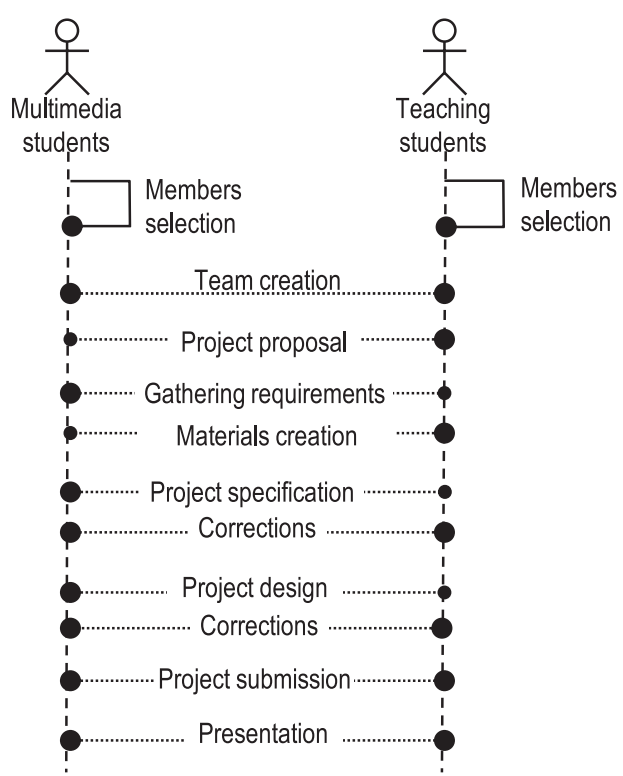

Fig. 1. Coordination stages for interdisciplinary teams.

role of being the general coordinator. For the experimental group, since the different schedules of the two degree programs meant that the UA and DP students were not often together, in each interdisciplinary group, one UA student and one DP student took the role of communication manager with the other course. The interdisciplinary teams met during the joint class sessions. Fig. 1 shows the interactions between both parts of the interdisciplinary teams; the size of the dots in each timeline represents the level of responsibility. 
TABLE II

ITEMS COVERED IN THE UA ASSESSMENT-TOOLS ARE IDENTIFIED IN TABLE III

\begin{tabular}{l|ll}
\hline \hline Feature & Tool & $\%$ \\
\hline Visibility & 1 & 7.5 \\
Operability & 1 & 7.5 \\
Intelligibility & 1 & 7.5 \\
Robustness & 1 & 7.5 \\
Use of headings & 2 & 2.5 \\
Use of highlighting and emphasis & 2 & 2.5 \\
Use of text design elements & 2 & 2.5 \\
Distribution of areas & 3 & 5 \\
Heading on all pages & 2 & 5 \\
Background/font contrast & 2 & 5 \\
Background images & 2 & 5 \\
Appropriate font size & 2 & 5 \\
Appropriate text width & 2 & 5 \\
Text Alignment & 2 & 5 \\
Gunning Fog Index & 2 & 5 \\
Number of broken links & 5 & 5 \\
Link redundancy percentage & 4 & 5 \\
Use of textual variants & 2 & 5 \\
Syntax errors & 6.7 & 7.5 \\
\hline \multicolumn{2}{|l}{}
\end{tabular}

TABLE III

Tools Used IN THE AsSEssment of UA

\begin{tabular}{|c|c|c|}
\hline$\overline{I d}$ & Tool & Description \\
\hline 1 & TAW & $\begin{array}{l}\text { Accessibility validation tool (Test de } \\
\text { Accesibilidad Web) } \\
\text { (http://www.tawdis.net/) }\end{array}$ \\
\hline 2 & jQuery & Javascript library \\
\hline 3 & Firefox Inspector & $\begin{array}{l}\text { Toolbar integrated into the Firefox } \\
\text { browser }\end{array}$ \\
\hline 4 & $\begin{array}{l}\text { Web Developer } \\
\text { Toolbar }\end{array}$ & $\begin{array}{l}\text { Plugin for Firefox browser developers. } \\
\text { (http://chrispederick.com/work/web- } \\
\text { developer/) }\end{array}$ \\
\hline 5 & W3C - Link Checker & $\begin{array}{l}\text { World Wide Web Consortium (W3C). } \\
\text { Web tool for checking links. } \\
\text { (http://validator.w3.org/checklink) }\end{array}$ \\
\hline 6 & $\begin{array}{l}\text { W3C - Markup } \\
\text { Validation Service }\end{array}$ & $\begin{array}{l}\text { Web tool to validate HTML syntax } \\
\text { (http://validator.w3.org/) }\end{array}$ \\
\hline 7 & $\begin{array}{l}\text { CSS Validation } \\
\text { Service }\end{array}$ & $\begin{array}{l}\text { Web tool to validate CSS syntax } \\
\text { (https://jigsaw.w3.org/css-validator/) }\end{array}$ \\
\hline
\end{tabular}

\section{Assessment}

This study only analyzes the performance of the multimedia UA students; the assessment of their activities is presented here. As previously noted, they carry out two practical tasks, in both of which they develop a Web-based product; each task is graded on a range from 0 to 10 using automated methods and tools that evaluated the products' UA according to the UA metrics listed in Table II. The table also shows the tool used (as identified in Table III) and the weight of each item in the final grade. The assessment criteria are explained to students at the start of the practical sessions.

Table III summarizes all of the tools used to assess the two Web products designed and developed by the multimedia students. The computer tools provide an objective measure of the students' academic performance, as discussed in the next sections.

Among these tools, jQuery, a general-purpose JavaScript library, was used in the analysis to locate and account for specific HTML features required by the activity. It was used to write a script that automated the analysis and validation of all the specified features.

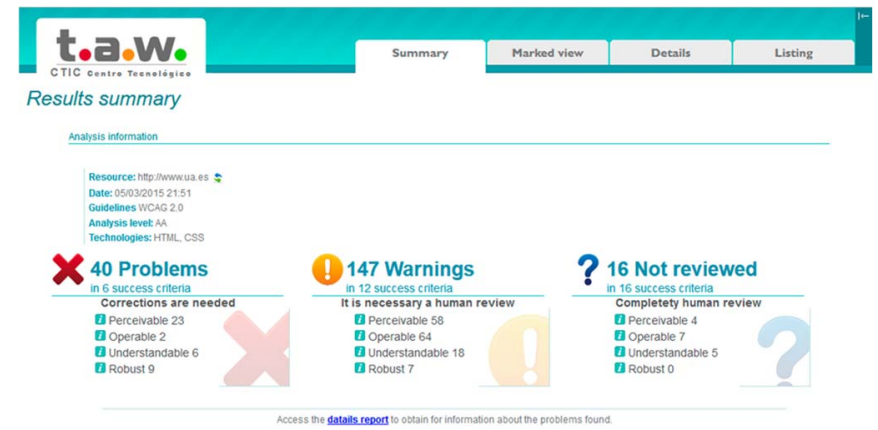

Fig. 2. Results obtained from the Web accessibility tool.

Accessibility features were mainly evaluated using the TAW tool (see Fig. 2), a Web application for validating Web pages according to the Web Content Accessibility Guidelines standard (WCAG-http://www.w3.org/WAI/intro/wcag). WCAG is considered the de facto standard for Web accessibility and was developed with the support of the main businesses in the sector.

\section{EXPERIMENTS}

The results presented in this paper focus exclusively on the performance of multimedia students. In addition to the experimental groups in both the multimedia and teaching programs, there were also control groups for each degree group who completed the tasks without interacting with students from the other degree programs. In both experimental and control groups, the assignment of tasks and the assessment methods were the same.

The statistical procedure used the general linear model with repeated measures, with the grade obtained for the Web product being taken as the dependent variable. The time of assessment (pretest and posttest) was used as the intrasubject factor, and participation in the interdisciplinary experiment (belonging to the experimental or control group) was the intersubject factor. All statistical analyses were conducted using SPSS (version 21.0).

Sample normality analysis indicated that the population follows a normal distribution. The result of the Box's $M$ test shows the homogeneity of the variance covariance matrix $(M=1.193, p=0.769)$.

To assess the program's impact on student performance, the grades obtained by both groups were compared prior to (pretest: week 6) and after the experiment (posttest: week 15). The pretest ( $\mathrm{p} 1$ ) consisted of the assessment of the first Web product in the course (weeks 1-6; see Table I) before the interdisciplinary intervention. The posttest consisted of assessing the second Web product of the course for which the intervention was carried out (weeks 7-15; see Table I). Belonging to one group or the other was the independent factor or variable, and the scores obtained by the students in these Web products were the criteria or dependent variables. The performance assessment being made automatically by a computer program (see Section II-D) avoids introducing any bias from a human evaluator's subjectivity.

The values of the intersubject test (see Table IV) indicate that the means of all observations differ from 0 because the tests have been shown to be significant $(p<0.000)$ for intersection but not for group belonging $(p=0.201)$. This finding confirms 
TABLE IV

TEST OF INTERSUBJECT EFFECTS

\begin{tabular}{rrrcc}
\hline \hline Source & Type III error & $G l$ & $F$ & Sig. \\
\hline Intersection & 5651.237 & 1 & 2399.799 & 0.000 \\
Group & 3.965 & 1 & 1.684 & 0.201 \\
Error & 105.970 & 45 & & $1)$ \\
\hline \hline
\end{tabular}

TABLE V

TEST OF INTRASUBJECT EFFECTS

\begin{tabular}{ccccccc}
\hline \hline Source & $\begin{array}{l}\text { Type III } \\
\text { error }\end{array}$ & Gl & $F$ & Sig. & $\begin{array}{c}\eta^{2} \\
\text { partial }\end{array}$ & $\begin{array}{l}\text { Ob. } \\
\text { Pow. }\end{array}$ \\
\hline Apl & 12.285 & 1 & 17.495 & 0.000 & 0.280 & 0.983 \\
Gr*Apl & 15.417 & 1 & 21.955 & 0.000 & 0.328 & 0.996 \\
Error & 31.600 & 45 & & & & \\
\hline \hline
\end{tabular}

TABLE VI

Student's T-Test ON THE DifFERENCE IN MEANS

\begin{tabular}{rlllll}
\hline \hline $\mathrm{pr}$ & $t$ & $g l$ & Sig. & Diff. & Std dev. \\
\hline 1 & -1.107 & 45 & 0.274 & -0.400 & 0.3607 \\
2 & 2.347 & 45 & 0.023 & 1.240 & 0.5286 \\
\hline \hline
\end{tabular}

that there are no initial significant differences between the two groups of students.

For the implementation of the program, Table $\mathrm{V}$ shows the test for intrasubject effects. The values resulting from the test show that the effect of the interaction between the time of assessment (pretest and posttest) and the implementation of the interdisciplinary program is significant $(p=0.000)$. The observed power is 0.996 , rejecting the null hypothesis of the equality of means. The effect size $\eta^{2}$, proportion of total variability attributable to a factor [43], or the magnitude of the difference between one time and another [44], resulting from the interaction between the time of the assessment and the implementation of the program, is 0.328 .

Finally, to test whether there is any difference between the experimental group and the control group, at the time of pretest and posttest, a Student's t-test on the difference in means was conducted (see Table VI), which shows that there were no significant differences at the time of pretest. This finding could mean that both groups began in comparable situations, which was already suggested by the intersubject test. For the posttest, the test shows a significant difference between the two groups $(p=0.023)$; this difference is 1.24 points higher in the experimental group.

Fig. 3 shows the scores obtained by both groups before and after the interdisciplinary intervention. In the posttest, the experimental group who had worked with the teaching students had higher scores, whereas the control group who had had no interdisciplinary interaction had worse performance.

\section{Discussion AND ConClusion}

The experimental results show different findings for the experimental group and the control group. First, when focusing exclusively on traditional teaching (control group and experimental group before the pretest), a worse group performance

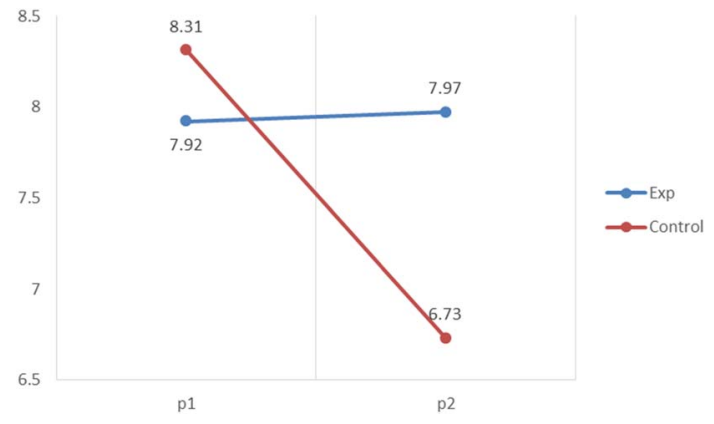

Fig. 3. Academic performance of the groups at pretest (p1) and posttest (p2).

can be observed. This decrease is significant in comparison to the experimental group, as shown in the intrasubject test in Table V. This decrease may be due to the fact that the posttest is more difficult than the pretest, which is conducted at a time when student knowledge is still limited.

For the experimental group, the usual tendency of obtaining lower scores than the initial test is not seen. Despite the difficulty of the posttest, there was a mild improvement, and the relatively improved results achieved by the experimental group are considered to be relevant. Contrasted with the Student's t-test for comparison with the control group, this improvement is significant because it cannot be attributed to chance nor can it be attributed to a subjective assessment on behalf of the evaluator, having been made by a computer program. In the opinion of the teaching staff involved in the experiment, this improvement could be due to two factors, i.e., motivation and interdisciplinarity.

As a general rule, a greater level of involvement was observed in the experimental groups, evidencing a greater effort on the part of the students while completing the project. The fact that they belonged to different degree programs increased their level of responsibility so that the engineers, as in the professional world, were able to realize a project from an interdisciplinary point of view.

Undoubtedly, creativity is one of the big advantages of working in interdisciplinary teams. From a psychological perspective, group work is presented as a potential vehicle for generating ideas that transcend the social inhibitions that are produced when working in a team [45]. From the engineering approach, interdisciplinary work is shown as key to increasing performance in the development of new products [46]. In line with these results, the professors observed better outcomes in the Web applications made by students in the experimental group. It can be also speculated that imagining items of appeal to children yields a rich variety of ideas.

In conclusion, this paper has shown that it is possible to improve the academic performance of multimedia engineering students through a program of interdisciplinary practical sessions that overlap other courses in the curriculum. This training program emulates a professional environment in the classroom that benefits engineering students.

Educators in similar programs will find it easier to integrate such an interdisciplinary intervention than to overload students with extracurricular courses that enhance teamwork but take time from their training in specific competences. 
TABLE VII

Multimedia DegreE-SPECIFIC S KILLS

\begin{tabular}{|c|c|}
\hline$\overline{I I D}$ & Skill \\
\hline$\overline{\mathrm{S} 1}$ & $\begin{array}{l}\text { Capacity to design, develop, assess and ensure accessibility, } \\
\text { ergonomics, usability and security of the multimedia systems, } \\
\text { services and applications, as well as the information managed. }\end{array}$ \\
\hline S2 & $\begin{array}{l}\text { Capacity to define, evaluate and select hardware and software } \\
\text { platforms for developing and executing multimedia systems, } \\
\text { services and applications. }\end{array}$ \\
\hline S3 & $\begin{array}{l}\text { Knowledge of basic materials and technologies which provide } \\
\text { the skills for learning and developing new methods and } \\
\text { technologies, as well as leading to considerable versatility in } \\
\text { adapting to new situations. }\end{array}$ \\
\hline S4 & $\begin{array}{l}\text { Capacity to resolve problems using initiative, decision making, } \\
\text { autonomy and creativity. Knowing how to communicate and } \\
\text { transmit knowledge, skills and abilities of the Multimedia } \\
\text { Engineering profession. }\end{array}$ \\
\hline S5 & $\begin{array}{l}\text { Capacity to work in an interdisciplinary group in a multilingual } \\
\text { environment, able to communicate in writing and orally } \\
\text { knowledge, procedures, results and ideas relating to } \\
\text { Information and Communications Technologies and more } \\
\text { specifically, the multimedia aspects of those technologies. }\end{array}$ \\
\hline S6 & $\begin{array}{l}\text { Capacity to handle any source of information relating to the } \\
\text { qualification, including bibliography and online materials in the } \\
\text { form of texts, images, sound or video. }\end{array}$ \\
\hline
\end{tabular}

TABLE VIII

UA GOALS

\begin{tabular}{ll}
\hline \hline ID & \multicolumn{1}{c}{ Goal } \\
\hline G1 & $\begin{array}{l}\text { To develop, maintain, manage, and evaluate multimedia services } \\
\text { and systems that satisfy all user requirements and perform } \\
\text { reliably, efficiently, and in compliance with quality standards. }\end{array}$ \\
G2 & $\begin{array}{l}\text { To create, design, and evaluate human-computer interfaces } \\
\text { ensuring accessibility and usability. }\end{array}$ \\
G3 & $\begin{array}{l}\text { To design, produce, and manage multilingual and multimodal } \\
\text { systems of multimedia content with the aim of ensuring its } \\
\text { internationalization, localization, accessibility, and usability. }\end{array}$ \\
\hline \hline
\end{tabular}

Curricular designs should integrate interdisciplinary perspectives that allow students to think about the strengths and limitations of their discipline. It is important to consider the value of other disciplinary perspectives, to prepare students to work effectively in teams [31], and to enable students to succeed in the job market with its variety of disciplines.

A limitation of this study is the significant effort needed by the teaching staff to enable students from completely different degrees to interact. This may well be easier to implement in generalist universities as they share a common campus. Furthermore, time constraints meant that it was not possible to include a subsequent study using interviews or contrasting instruments for measuring EI (BarOn test, Mayer-Salovey-Caruso Emotional Intelligence test, etc.), which could give us an idea of the impact that this intervention had on the actual skills of the EI.

As future research work, the authors are considering applying this interdisciplinary approach to all the courses in an academic year of the Multimedia Engineering program and analyzing its impact on the students' academic performance and EI through contrasting instruments.

\section{APPENDIX}

Tables VII-IX are presented here.
TABLE IX

RESUlTS OF THE LEARNING PROPOSED IN UA

\begin{tabular}{ll}
\hline \hline$I D$ & \multicolumn{1}{c}{ Source } \\
\hline R1 & Ease of learning for the user \\
R2 & Flexibility in use of interfaces \\
R3 & Interface consistency \\
R4 & Robustness, integrity and control of errors \\
R5 & Recoverability in the event of status changes \\
R6 & Acceptable response times \\
R7 & Adaptation to tasks \\
R8 & Reduction of the cognitive load \\
R9 & Provide equivalent alternatives for audiovisual content. \\
R10 & Independence from colour \\
R11 & Use of markers and style sheets \\
R12 & Clarify use of natural language \\
R13 & Ensure user control over changes in time sensitive content \\
R14 & Ensure direct accessibility of embedded user interfaces \\
R15 & Design of device independence \\
R16 & Use of standard technologies \\
R17 & Provide contextual information and guidance \\
R18 & Provide clear navigation mechanisms \\
R19 & Ensure that documents are clear and simple \\
\hline \hline
\end{tabular}

\section{REFERENCES}

[1] F. J. Sánchez, F. Aparicio, M. A. Alvarez, and F. Jimenez, "SAE formula project for developing personal and professional skill in automotive engineers," Int. J. Eng. Educ., vol. 25, no. 3, pp. 585-594, 2009.

[2] C. M. Brotheridge, "The role of emotional intelligence and other individual difference variables in predicting emotional labor relative to situational demands," Psicothema, vol. 18, pp. 139-144, 2006.

[3] M. L. Pertegal-Felices, J. L. Castejón-Costa, and A. Jimeno-Morenilla, "Differences between the personal, social and emotional profiles of teaching and computer engineering professionals and students," Stud. Higher Educ., vol. 39, no. 7, pp. 1185-1201, 2014.

[4] M. L. Pertegal-Felices, J. L. Castejon-Costa, and A. Jimeno-Morenilla, "Personal and emotional skill profiles in the professional development of the computer engineer," Int. J. Eng. Educ., vol. 26, no. 1, pp. 218-226, 2010

[5] B. Ayuste, A. Gros, and S. Valdivieso, "Sociedad del conocimiento. Perspectiva pedagógica," in Sociedad Del Conocimiento y Educación, L. García, Ed. Madrid, Spain: UNED, 2012, pp.17-40.

[6] R. Bar-On, "Emotional and social intelligence: Insights from emotional quotient inventory," in The Handbook of Emotional Intelligence: Theory, Development, Assessment, and Application at Home, School, and in the Workplace, R. Bar-On and J. D. A. Parker, Eds. San Francisco, CA, USA: Jossey-Bass, 2000, pp. 343-362.

[7] C. Cherniss, "Emotional intelligence: What it is and why it matters," in Proc. Аnпu. Meet. Soc. Ind. Org. Psychol., New Orleans, LA, USA, 2000, vol. 15, pp. 1-14.

[8] J. D. Mayer and P. Salovey, "What is emotional intelligence?" in Emotional Development and Emotional Intelligence: Educational Applications, P. Salovey and D. Sluyter, Eds. New York, NY, USA: Basic Books, 1997, pp. 3-31.

[9] R. Boyatzis, D. Goleman, and K. Rhee, "Clustering competence in emotional intelligence: Insights from the Emotional Competence Inventory (ECI)," in Handbook of Emotional Intelligence, R. Bar-On and J. D. A. Parker, Eds. San Francisco, CA, USA: Jossey-Bass, 2000, pp. 343-362.

[10] K. S. Law, C. S. Wong, and L. Song, "The construct and criterion validity of emotional intelligence and its potential utility for management studies," J. Appl. Psychol., vol. 89, no. 3, pp. 483-496, Jun. 2004.

[11] J. Mayer, P. Salovey, and D. Caruso, "Competing models of emotional intelligence," in Handbook of Human Intelligence, 2nd ed., R. J. Sternberg, Ed. New York, NY, USA: Cambridge Univ. Press, 2000, pp. 396-420.

[12] R. Bar-On, "The Emotional Quotient Inventory (EQ-i): Technical manual," Multi-Health Syst., Inc., Toronto, ON, Canada, 1997.

[13] M. Zeidner, G. Matthews, and R. Roberts, "Development of emotional intelligence: Towards a multi-level investment model," Hum. Develop., vol. 46, no. 2/3, pp. 69-96, 2003.

[14] E. S. Koman and S. B. Wolff, "Emotional intelligence competencies in the team and team leader: A multi-level examination of the impact of emotional intelligence on team performance," J. Manage. Develop., vol. 27, no. 1 , pp. 55-75, 2008 
[15] R. E. Boyatzis, "Competencies in the 21st century," J. Manage. Develop., vol. 27, no. 1, pp. 5-12, 2008

[16] D. W. Chan, "Emotional intelligence and components of burnout among Chinese secondary school teachers in Hong Kong," Teaching Teacher Educ., vol. 22, no. 8, pp. 1042-1054, Nov. 2006.

[17] J. P. Grayson, "Social dynamics, university experiences, and graduates' job outcomes," Brit. J. Sociol. Educ., vol. 25, pp. 609-627, 2004.

[18] G. R. Burns, C. U. Chisholm, and M. S. G. Blair, "Academic and workplace profiles of engineering professional development," in Proc. 11th Baltic Region Semin. Eng. Educ., 2007, pp. 18-20.

[19] R. Van der Velden and J. Allen, The Flexible Professional in the Knowledge Society: Required Competences and the Role of Higher Education. Amsterdam, The Netherlands: Springer-Verlag, 2011, pp. 15-53.

[20] J. González and R. Wagenaar, Tuning Educational Structures in Europe II. Bilbao, Spain: Deusto Univ. \& Groningen Univ., 2004.

[21] C. Cherniss and M. Adler, Promoting Emotional Intelligence in Organizations: Make Training in Emotional Intelligence Effective. Alexandria, VA, USA: American Society Training Development, 2000.

[22] N. Clarke, "Emotional intelligence training: A case of caveat emptor," Hum. Resour. Develop. Rev., vol. 5, no. 4, pp. 422-441, 2006.

[23] J. González and R. Wagenaar, Tuning educational structures in Europe, Univ. Deusto, Bilbao, Spain, Final Rep., 2003.

[24] "Career space project. Curriculum development guidelines: New ICT curricula for the 21st century, designing tomorrow's education," Office Official Publications Eur. Commun., Luxembourg, U.K., 2001.

[25] N. Hotaling, B. B. Fasse, L. F. Bost, C. Hermann, and C. R. Forest, "A quantitative analysis of the effects of a multidisciplinary engineering capstone design course," J. Eng. Educ., vol. 101, no. 4, pp. 630-656, Oct. 2012

[26] M. Elias et al., Promoting Social and Emotional Learning: Guidelines for Educators. Alexandria, VA, USA: Association Supervision Curriculum Development, 1997.

[27] J. E. Zins, W. Weissberg, and Walberg, Building Academic Success on Social and Emotional Learning: What Does the Research Say? New York, NY, USA: Teachers College Press, 2004.

[28] U. Oberst, J. Gallifa, N. Farriols, and A. Vilaregut, "Training emotional and social competences in higher education: The seminar methodology," Higher Educ. Eur., vol. 34, no. 3/4, pp. 523-533, 2009.

[29] D. C. Lopes, M. C. Gerolamo, Z. A. P. Del Prette, M. A. Musetti, and A. Del Prette, "Social skills: A key factor for engineering students to develop interpersonal skills," Int. J. Eng. Educ., vol. 31, no. 1B, pp. 405-413, 2015.

[30] B. Bond and R. Manser, "Emotional intelligence interventions to increase student success," Higher Educ. Quality Council Ontario, Toronto, ON, Canada, 2009.

[31] L. Lattuca and D. Knight, "In the eye of the beholder: Defining and studying interdisciplinarity in engineering education," in Proc. Amer. Soc. Eng. Educ. Аnпu. Conf. Expo., Louisville, KY, USA, 2010, pp. 1-24.

[32] J. T. Klein and W. T. Newell, "Advancing interdisciplinary studies," in Handbook of the Undergraduate Curriculum: A Comprehensive Guide to Purposes, Structures, Practices, and Change, J. G. Gaff and J. L. Ratcliff, Eds. San Francisco, CA, USA: Jossey-Bass, 1996.

[33] A. Dirsch-Weigand et al., "Looking beyond one's own nose right from the start: Interdisciplinary study projects for first year engineering students," in Proc. IEEE Int. Conf. ICL, Sep. 2015. pp. 729-732.

[34] D. M. Richter and M. C. Paretti, "Identifying barriers to and outcomes of interdisciplinarity in the engineering classroom," Eur. J. Eng. Educ., vol. 34, no. 1, pp. 29-45, 2009.

[35] S. Vosniadov, C. Ioannides, A. Dimitrakopoulou, and E. Papademetriv, "Designing learning environments to promote conceptual change in science," Learn. Instruction, vol. 11, pp. 381-419, 2001.

[36] M. M. Capraro and M. Jones, "Interdisciplinary STEM projectbased learning," in STEM Project-Based Learning. Dordrecht, The Netherlands: Sense, 2013, pp. 51-58.

[37] D. Verhaest and R. Van der Velden, "Cross-country differences in graduate overeducation," Eur. Sociol. Rev., vol. 29, pp. 642-653, 2013.

[38] V. Valls, V. González-Romá, A. Hernández, J. Yeves, and J. P. Gamboa, "Quality of education and new entrants' job search intensity: The mediating role of general self-efficacy," presented at the16th Congress European Association Work Organizational Psychology, Münster, Germany, 2013.
[39] R. Kanfer, C. R. Wanberg, and T. M. Kantrowitz, "Job search and employment: A personality-motivational analysis and meta-analytic review," J. Appl. Psychol., vol. 86, no. 5, pp. 837-855, Oct. 2001.

[40] S. R. Goldman and A. J. Petrosino, "Cognition and technology group at Vanderbilt. Design principles for instruction in content domains: Lessons from research on expertise and learning," in Handbook of Applied Cognition, F. T. Durso et al., Eds. New York, NY, USA: Wiley, 1999, pp. 595-627.

[41] E. De Corte, "Marrying theory building and the improvement of school practice: A permanent challenge for instructional psychology," Learn. Instruction, vol. 10, no. 3, pp. 249-266, 2000.

[42] B. Oakley, R. Brent, R. Felder, and I. Elhajj, "Turning student groups into effective teams," J. Student Centered Learn., vol. 2, no. 1, pp. 9-34, 2004.

[43] H. Gardner, "Multiple intelligences after twenty years," in Proc. Amer. Educ. Res. Assoc., Chicago, IL, USA, 2003, vol. 21, pp. 1-14.

[44] R. Ledesma, G. Macbeth, and N. Cortada De Kohan, "Effect size: A conceptual review and applications with the ViSta statistical system," Revista Latinoamer. Psicol., vol. 40, no. 3, pp. 425-439, 2008.

[45] P. Paulus, "Groups, teams, and creativity: The creative potential of idea-generating groups," Appl. Psychol., vol. 49, no. 2, pp. 237-262, Apr. 2000.

[46] J. Alves, M. J. Marques, I. Saur, and P. Marques, "Creativity and innovation through multidisciplinary and multisectoral cooperation," Creativity Innov. Manage., vol. 16, no. 1, pp. 27-34, 2007.

Diego Marcos-Jorquera was born in Spain in 1974. He received the Engineering degree in computer science in 1999 from the University of Alicante, Alicante, Spain, where he has been working toward the Ph.D. degree with the Department of Computer Technology since 2004.

$\mathrm{He}$ is currently an Associate Professor with the University of Alicante. His research interests are in the areas of network management, computer networks, and distributed systems.

María Luisa Pertegal-Felices was born in Spain in 1974. She received the B.S. degree in psychology and pedagogy and the Ph.D. degree from the University of Alicante, Alicante, Spain, in 2011.

She is currently an Assistant Lecturer with the Department of Development Psychology and Teaching, University of Alicante. She also has more than ten years of child guidance experience at public schools. Her research interests include emotional intelligence applied to work performance, investigation of higher education, and the development of generic competencies.

Antonio Jimeno-Morenilla (M'06) was born in Spain in 1970. He received the Ph.D. degree in computer engineering from the University of Alicante, Alicante, Spain, in 2003.

$\mathrm{He}$ is currently an Associate Professor with the Department of Computer Technology, University of Alicante. His research interests include computational geometry for design and manufacturing, rapid and virtual prototyping, and high-performance computer architectures. He also has considerable experience in the investigation of the professional skills of computer engineers.

Raquel Gilar-Corbí was born in Spain in 1974. She received the Ph.D. degree in educational psychology from the University of Alicante, Alicante, Spain, in 2002.

Since 2003, she has been with the University of Alicante, where she is currently an Associate Professor with and the Director of the Department of Development Psychology and Teaching. She has managed and participated in numerous research projects, both national and international. Her research interests are focused on intelligence, underachievement, high abilities, emotional intelligence, and teacher training. 